\title{
The Empirical Research on Impact Mechanism of Cross-Cultural Leadership to Leadership Effectiveness
}

\author{
Bin $\mathrm{HE}^{1}$, Zeying $\mathrm{LI}^{*}{ }^{* 1,2}$, Hong ZHENG ${ }^{1}$, Changzhi MA ${ }^{1}$, Siying $\mathrm{LI}^{1}$ \\ ${ }^{1}$ School of Management, Guangdong University of Technology, Guangzhou, 510520, P.R. China \\ ${ }^{2}$ Hanshan Normal University, Chaozhou, 521000, P.R. China \\ *lizeyld@163.com
}

\begin{abstract}
As a product of economic globalization and internet economy, Cross-cultural Teams (CCTs) are increasingly becoming an important organizational form of multinational corporations and multinational organizations. However, what are the motive powers of CCTs'leadership effectiveness? What is the influencing mechanism of the motive powers? What are the mediating effect and moderating effect in the above leadership process? These theoretical questions haven't been solved effectively at present. Considering the Sino-Germany CCTs as the research object and based on cross-cultural management theory and empirical method, the paper explores the mechanism how Sino-Germany CCTs leadership influences the leadership effectiveness from perspectives of influencing mode and influencing effectiveness. The conclusions of this research a re as follows: Sino-Germany CCTs leadership exercises its influence on leadership effectiveness through leadership object's cognition of leadership as intermediary variable; its process is also restricted by individual-team matching degree; in addition, leadership effectiveness is influenced by the cultural background of principal leaders in the team.
\end{abstract}

Keywords: Cross-cultural Leadership, Leadership Effectiveness, Impact Mechanism, Sino-Germany CrossCultural Teams.

\section{INTRODUCTION}

With the development of economic globalization and the Internet economy, more and more German companies entering China and plays an important role in the development of Chinese enterprises such as Siemens, Volkswagen, and TUV Rheinland Group. At the same time, more and more Chine se multinational companies are opening up German market with their might and main such as Haier, Lenovo and Huawei so on. With the popularity of cross-cultural business model, more and more multinational companies pay more attention to cultivating talents, who is able to adapt to the crosscultural environment. Especially in the rapid development of the internet today, these companies, and other small and medium enterprises, are also committed to the construction of Cross-cultural Teams (CCTs) (He, B., Li, Z.Y., Zheng, H. 2014; Zheng, H., 2014). Thus, CCT has become a typical model with the current characteristics of the times of global organizations (He, B., et. al., 2014). CCT's advantage lies in its integration of resources belonging to different cultures and capability information to a team with a high potential for cultural creation and cultural synergies. But its disadvantages are also obvious, for example, it has increased the complexity of the organization and leadership, increase the risk of conflict arising due to cultural differences (including language conflict, conflict behavior, customs and values conflict conflict), a serious impact on the effectiveness of the team's leadership.

Researcher (Zheng, H., 2014) drew the cultural differences and cultural conflicts through depth interview of SIEMENS, Volkswagen, Haier and Lenovo and other Sino-German CCTs. For example, the problems of a German cross-cultural team are as follow: ( a) in the cross-cultural background, if the leadership styles of leaders and subordinates did not match, the leadership effectiveness was not high; (b) the team of new employees had to adapt cross-cultural training environment, but there was "fragmentation" problem, just let new people into the Chinese culture to adapted to Germany, but the Germans did not allow new entrants to adapted to Chinese culture; (c) leaders did not understand the key work of the different cultural members and how to had high job satisfaction, thus result in ineffective incentives and ineffective promotion; (d) the mismatching between individual and the work environment will lower the leadership effectiveness of team. 
For the needs of survival and development of enterprises in the international market, leadership and effective leadership effectiveness as an indispensable hardware, determines the core competitiveness of enterprises (Shu, S. F., 2014). From the perspective of corporate managers, the content structure of CCT leadership and leadership effectiveness issues has become the most important task in the management of CCT, thus grow into a "significant productivity". Therefore, the study of leadership and leadership CCT affect the effectiveness of the mechanism, Yangchangbuduan, so as to enhance the effectiveness of CCT's leadership, it has become the urgent needs of many transnational organizations and multinational development.

Professor He have proposed and verified the cross-cultural leadership content structure in 2014, got a the two-rank two-factor model of cross-cultural leadership composed of six variables (He, B., et. al., 2014). But the problem is closely related, such as dynamic cross-cultural leadership effectiveness is what? Influence mechanism of this power is what? How to improve cross-cultural leadership effectiveness? And so on, these problems have not been effectively resolved. In cross-cultural studies, with the main research object of Sino-American cross culture, more and more scholars pay attention to the study of Chinese and European cross culture.

Sino-German CCT mainly takes Chinese enterprise culture as the main culture, which is a typical example of China-European CCT. The research results are helpful to the CCT team to clarify the power source of the leadership effectiveness, and also enrich the results of the Chinese-European cross-cultural studies.

Therefore, the paper takes the German $\mathrm{T}$ group as the research object, and uses the empirical method to study the influence mechanism of cross-cultural leadership on the leadership effectiveness in SinoGerman CCT. And take an in-depth study through its impact mode, what factors limit the impact process, the effectiveness of the influence, and so on. It is desirable to gradually open black box of the Sino-German CCT impact mechanism on leadership effectiveness, and lay a theoretical basis foundation for the further development of the CCT leadership effectiveness.

\section{LITERATURE REVIEW}

\subsection{Cross-Cultural Leader and Cross-Cultural Leadership}

Cross-cultural leadership theory is developed on the basis of leadership theory, which is the theoretical set of effective leadership in cross-cultural context (He, B., et. al., 2014). Different from the group with a single cultural background, cross-cultural groups are endowed with new connotation of the cross culture. Because of the cultural diversity and the cultural impact of the cultural issues, it will be difficult for the management of cross-cultural groups and effective leadership (Chen, X. P., 2009). At present, there are plentiful achievements of the concept of cross-cultural leadership, cultural perception of leadership, culture leads to different leadership behavior, ross-cultural leadership skills and quality, and so on(He, B., et. al., 2014; Brodbeck, F. C. et. al.,2000; Hartog, D. N. D., et. al.,1999; Ensari, N., \&Murphy, S. E. ,2003; Elenkov, D. S., \& Manev, I. M. ,2005; Spitzberg, B. H.,1998; Thoms, P., \& Greenberger, D. B. ,1995) .

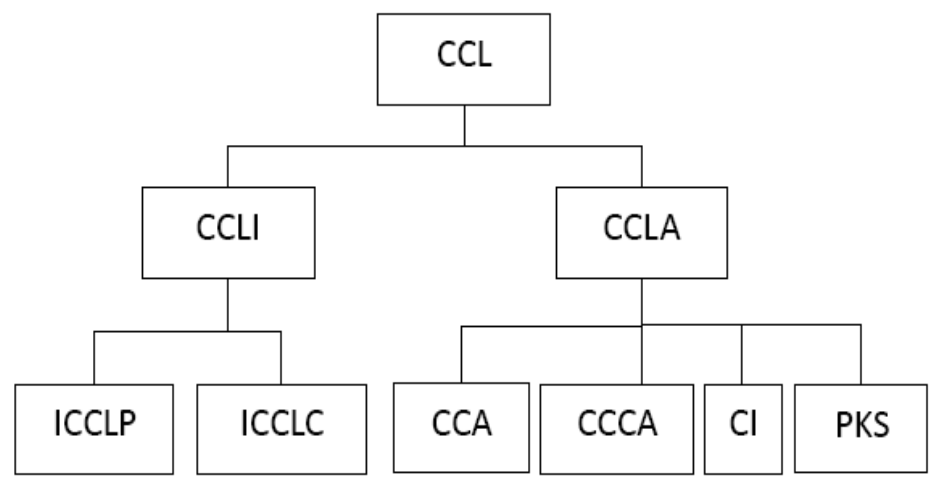

CCL: Cross-cultural leadership
CCLI: Cross-cultural leading influence
ICCLP:The influence of cross-cultural leader's
power
ICCLC:The influence of cross-cultural leader's
charisma
CCLA:Cross-cultural leading ability
CCA:Cross-Cultural Adaptability
CCCA:Cross-Cultural Communication Ability
CI:Cultural Integration ability
PKS:Professional Knowledge and Skills

Fig1. The content structure of cross-cultural leadership

Cross-cultural leadership is a leadership in itself. Combing domestic and foreign scholars on the definition of leadership, there are mainly three kinds of impact on a wide range of views :(1) leadership is the influence (Koontz, H.,1980; Weihrich, H., 1979);(2) Leadership is the leading ability 
(Bennis, W., \& Goldsmith, J.,1997);(3) Leadership is a comprehensive power (He, B., et. al., 2014). From the definition of leadership, cross-cultural leadership is a multi-factor interaction power. In this paper, the concept of cross-cultural leadership and its content structure mainly refers to the achievements in previous scientific research of our team. It refers to the sum of the power of the leader subject in the process of leading and guiding the leader object to achieve the goal of the team (or organization) in the cross-cultural context (He, B., et. al., 2014; Zheng, H., 2014). The content structure of cross-cultural leadership is shown in Fig.1, and ICCLP, ICCLC, CCA, CCCA, CI, PKS are called the six variables of cross-cultural leadership.

\subsection{Cross-Cultural Leadership Effectiveness}

There are currently has a relatively mature results of leadership effectiveness in the academia. According to the literature review, most scholars mainly focus on the relationship between leadership style and leadership effectiveness (Allameh, S. M., et. al., 2015; Torres, L. E., et. al., 2015; Deng, Z. H., Chen, W. Z., 2014; Hu, H. J., et. al., 2015; Yu, H. B., et. al., 2014; Lin, C. P., Zhuang, B.C., 2014), and some scholars focus on the relationship between leadership behavior and leadership effectiveness (Butler, A. M., et. al, 2014; Li, P., et. al.,2014; Wu, W.K., et. al.,2003), followership and leadership effectiveness (Zhou, W.J., et. al., 2015; Xu, S.,2013; Yuan, T., Ling, W.Q.,2010). But there is not yet found the achievement of the relationship research about the power of cross-cultural leadership effectiveness or cross-cultural leadership and leadership effectiveness (Allameh, S. M., et. al.,2015; Torres, L. E., et. al., 2015; Deng, Z. H., Chen, W. Z., 2014; Hu, H. J., et. al.,2015; Yu, H. B., et. al.,2014; Lin, C. P., Zhuang, B.C. ,2014). The relationship between corporate culture and leadership effectiveness is the most closely related to the research (Deng, Z. H., \&Chen, W. Z., 2014; Yao, Y.H., \&Jiang F.J., 2008).

Generally speaking, cross-cultural leadership effectiveness refers to the ability of leader object achieve the leader goal and the efficiency and effectiveness of the achievement (Zheng, H., 2014). In the theoretical research, all of the research on the leadership theory is due to the research of effectiveness of leadership, and the effectiveness of leadership is the problem of leadership effectiveness. Leadership effectiveness is a broad concept, and the measurement of leadership effectiveness depends on the different understanding of the concept of leadership. Scholar Fred E. Fiedler believes that effective leadership behavior depends on the influence between the leader and its subordinate, and some other scholars (Cosentino, C. J., et. al., 2004; Fiedler, F. E., 1971) consider that leadership effectiveness can be measured according to the observed actual performance team. In addition, House and Baetz (1979) considered that the degree of leadership effectiveness should be measured from the subordinate's satisfaction, the willingness of subordinates to fulfill the task, and the extent to which the leadership is accepted to the subordinates.

More recently, many scholars agreed that leadership effectiveness could be measured according to the performance and employee psychology and behavior, which performance referred to the objective performance data and the objective evaluation of the organization, and the main contents of employee psychology and behavior ware regarded as job satisfaction, organizational identification, organizational commitment, turnover intention and other measures (Li, X.Q., \& Lin, Z.Y.,2013; Qu, Q., et. al., 2013; Li, J., et. al., 2013; Bruno, L. F. C., \& Lay, E. G. E. , 2008; Wu, Z. M., \&Wu, X., 2006). Furtherly, the meta-analysis of leadership effectiveness (Wang, Z., et. al., 2012) suggested that the measure of leadership effectiveness could be divided into subordinate attitudinal variables and behavioral variables. According to this study (Wang, Z., et. al., 2012), the subordinate attitudinal variables included job satisfaction and team affective commitment, and the subordinate behavioral variables included job performance and organizational citizenship behavior. However, these studies had not clearly pointed out that the power source of leadership effectiveness was the leadership.

In a word, the research on impact mechanism of cross-cultural leadership to leadership effectiveness requires the researchers to make a further study on the specific cross-cultural context. This is the difficulty of the cross-cultural leadership research at present.

\section{HyPOTHESES AND THEORETICAL MODELS}

With reference to previous studies in cross-cultural leadership in defining and its content structure (He, B., et. al., 2014), we select the six variables as antecedent variables of theoretical research model, which come from the two-rank two-factor model of cross-cultural leadership. 
In deconstructing the outcome variable-the sub-dimensions of cross-cultural leadership effectiveness, we referred to Leadership Effectiveness in the Chinese Context: A Meta-Analysis of Transformational Leadership, Leader-Member Exchange and Abusive Supervision (Wang, Z., et. al., 2012), chose job satisfaction(JS) and team commitment (TC) as the subordinate attitudinal variables, and chose team leader citizenship behavior(TCB) and job performance (JP) as the subordinate behavioral variables (shown as the Fig.2). Among them, job performance was a comprehensive performance indicator including the staff quantifiable results of work, the behavior mode and physical and mental activity of completing the work process (Sonnentag, S., \& Frese, M., 2005); job satisfaction referred to an emotional and cognitive response that the subordinate of its work, and also referred to an subjective evaluation and attitude that the subordinate response to the working environment (Bono, J. E., \& Judge, T. A., 2003); team commitment referred to the psychological identity and emotion of the employees in the team, as well as the willingness to serve the team members of the psychological state (Tang, L. L., 2009); and the team citizenship behavior referred to the behavior which benefit to the team, but in the official salary system had not yet been confirm clearly or directly (Li, C. P., et. al.,2007). In this paper, the subordinates' job performance (JP), job satisfaction (JS), team commitment (TC) and team citizenship behavior (TCB) were used as the sub dimensions of the result variables: cross-cultural leadership effectiveness.

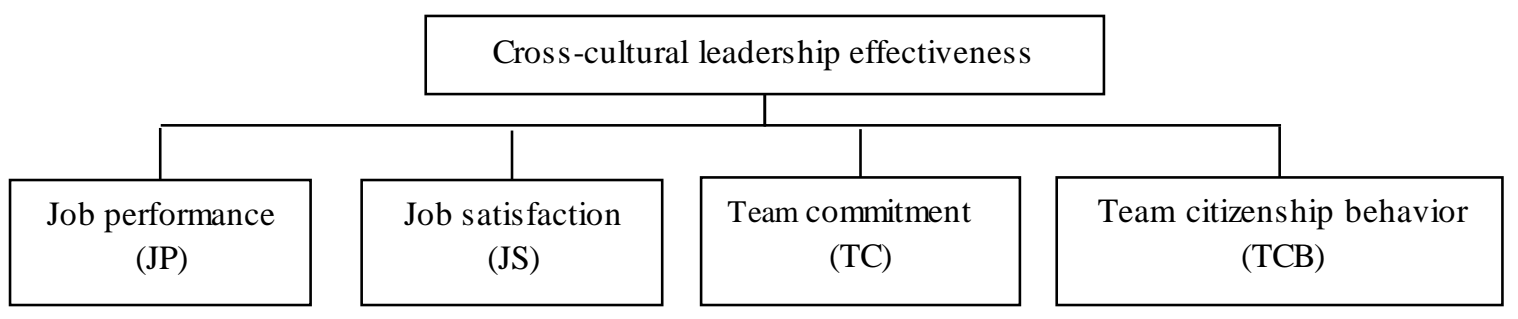

Fig2. Cross-cultural leadership effectiveness content structure

Some researchers (Xie, Y., et. al., 2013; A Nahavandi., 2000) believed that leadership in a large extent determined the effectiveness of leadership (or leadership effectiveness) and work performance, another researchers (Zenger, J. H., \& Folkman, J.R.., 2009) believed that leaders would improve leadership effectiveness through the development of personal leadership. Therefore, we believed that cross-cultural leadership had an impact on the leadership effectiveness, but in different cultural backgrounds, the degree of impact and influence may be inconsistent (Yuan, L., Li, Y., 2012; Chen, X., \& Zhu, X., 2015). Consequently, we present the first hypothesis:

H1: Cross-cultural leadership is the driving force of leadership effectiveness, and the impact effect of cross-cultural leadership on leadership effectiveness is influenced by the main cultural background of the team.

According to the differences of the leadership mechanism of Sino-German cross-cultural team (He, B. et. al., 2014), and in terms of the expression of the research hypothesis that proposed by Professor $\mathrm{Wu}$ (Wu, W. K., et. al., 2003), we can divide the hypothesis H1 into two types by two cultural backgrounds.

(1)In Chinese cultural background, the Chinese leaders are used to directive leadership. The Chinese leaders are good at using their own personal power and personal charisma to lead the team, which will bring a certain degree of team work performance, but it is easy to affect the degree of power to combat team members' confidence, enthusiasm and freedom to restrict members, so it may bring negative to job satisfaction, team commitment and team citizenship behavior. Of course, excellent cross-cultural adaptability, cross-cultural communication ability, cross-cultural adaptability and professional knowledge and skills will bring a positive impact on leadership effectiveness four variables. Therefore, in the Chinese context, the hypothesis $\mathrm{H}_{1}$ can divide into four hypotheses as follows:

$$
\begin{aligned}
& \mathrm{H}_{1 \mathrm{a} 1}: \mathrm{JP}=\mathrm{C}_{\mathrm{C}}(+\mathrm{ICCLP},+\mathrm{ICCLC},+\mathrm{CCA},+\mathrm{CCCA},+\mathrm{CI},+\mathrm{PKS}) \\
& \mathrm{H}_{1 \mathrm{a} 2}: \mathrm{JS}=\mathrm{C}_{\mathrm{C}}(-\mathrm{ICCLP},+\mathrm{ICCLC},+\mathrm{CCA},+\mathrm{CCCA},+\mathrm{CI},+\mathrm{PKS}) \\
& \mathrm{H}_{1 \mathrm{a} 3}: \mathrm{TC}=\mathrm{C}_{\mathrm{C}}(-\mathrm{ICCLP},+\mathrm{ICCLC},+\mathrm{CCA},+\mathrm{CCCA},+\mathrm{CI},+\mathrm{PKS}) \\
& \mathrm{H}_{1 \mathrm{a} 4}: \mathrm{TCB}=\mathrm{C}_{\mathrm{C}}(-\mathrm{ICCLP},+\mathrm{ICCLC},+\mathrm{CCA},+\mathrm{CCCA},+\mathrm{CI},+\mathrm{PKS})
\end{aligned}
$$


(2)In German cultural background, German leaders are used to collaborative and expert leadership style. Germany's leaders are more likely to use professional attitude and professional skills and knowledge to lead the team, the influence of cross-cultural leader's power (ICCLP) may ineffective in the German cultural background, thus remove the variable from the hypotheses. Compared with the Chinese leader, the German leader advocates the rules (Li, C. C., 2014) pay more attention to democracy (judgment by the economic information society and the establishment of democratic index) and good at using the Cross-cultural leading ability. Therefore, in the German context, the hypothesis $\mathrm{H}_{1}$ can divide into four hypotheses as follows:

$$
\begin{aligned}
& \mathrm{H}_{1 \mathrm{~b} 1}: \mathrm{JP}=\mathrm{C}_{\mathrm{G}}(+\mathrm{ICCLC},+\mathrm{CCA},+\mathrm{CCCA},+\mathrm{CI},+\mathrm{PKS}) \\
& \mathrm{H}_{1 \mathrm{~b} 2}: \mathrm{JS}=\mathrm{C}_{\mathrm{G}}(+\mathrm{ICCLC},+\mathrm{CCA},+\mathrm{CCCA},+\mathrm{CI},+\mathrm{PKS}) \\
& \mathrm{H}_{1 \mathrm{~b} 3}: \mathrm{TC}=\mathrm{C}_{\mathrm{G}}(+\mathrm{ICCLC},+\mathrm{CCA},+\mathrm{CCCA},+\mathrm{CI},+\mathrm{PKS}) \\
& \mathrm{H}_{1 \mathrm{~b} 4}: \mathrm{TCB}=\mathrm{C}_{\mathrm{G}}(+\mathrm{ICCLC},+\mathrm{CCA},+\mathrm{CCCA},+\mathrm{CI},+\mathrm{PKS})
\end{aligned}
$$

In the above formulae, symbol " $\mathrm{C}_{\mathrm{C}}$ " said team mainly on the Chinese cultural background (or team leader is Chinese), symbol " $\mathrm{C}_{\mathrm{G}}$ " said team mainly on the German cultural background (or team leader is German), symbol"+" indicates positive effect, symbol"-" indicates negative effects. Take hypothesis $\mathrm{H}_{1 \mathrm{a} 1}$ for example in detail: in Chinese cultural background, ICCLC, CCA, CCCA, CI, ICCLP and PKS have a positive effect on JP. Others hypotheses are similar.

Situational Leadership theory (Paul Hersey, 2003) believes that the effectiveness of leadership is a function of leaders, subordinate and environment interaction. The effectiveness of leadership is closely related to subordinate s' knowledge, experience, ability, cultural background, responsibility, perception and so on.

The impact of leadership effectiveness is subordinates' perceived leadership effects on the leadership (SPLEL)( Zheng, H.,2014; Meng, Y., et. al., 2014; Cogliser, C. C., et. al., 2009), other things of subordinate being equal.

Perception in psychology is defined as the stimulating physical information received by the human brain through its receptor (Mietzel, G., 2007). Similarly, subordinates' perceived leadership effects on the leadership (SPLEL) are the information and its effect of subordinates to receive that the leadership effect on it (Zheng, H., 2014). In the same context of cross-cultural leadership, the SPLEL will have a difference, which will affect the level of job performance, job satisfaction, team commitment, team citizenship behavior.

According to the stress analysis in the theory of physics, the magnitude of the force will also affect the effect (Shu, Y. S., 2005). Therefore, in the different context of cross-cultural leadership, the SPLEL also have a difference, thus affecting the level of leadership effectiveness. As a result, we introduce SPLEL as the mediator variable and proposed the following hypothesis:

$\mathrm{H}_{2}$ : SPLEL plays an intermediary role in cross-cultural leadership and JP, cross-cultural leadership and JS, cross-cultural leadership and TC, cross-cultural leadership and TCB.

Zenger, J. H. and Folkman, J.R. (2009) said that the play of leadership is closely related to the specific circumstances and situations. Situational Leadership theory (Paul Hersey, 2003) also believes that the effectiveness of leadership is the function of leader, the subordinate, the environment interaction. It can be concluded that the influence of cross-cultural leadership on the leadership effectiveness is not separated from the adjustment of the situation variable in terms of "leadership is influenced by the three factors: the leader, the subordinate and the leadership environment". Therefore, we are going to choose individual-team matching degree (ITMD) as the moderator variable in the light of Individual and Environment Matching Theory, and made the following hypotheses:

$\mathrm{H}_{3}$ : The main effect of cross-cultural leadership on the leadership effectiveness four variables will be regulated by ITMD. 


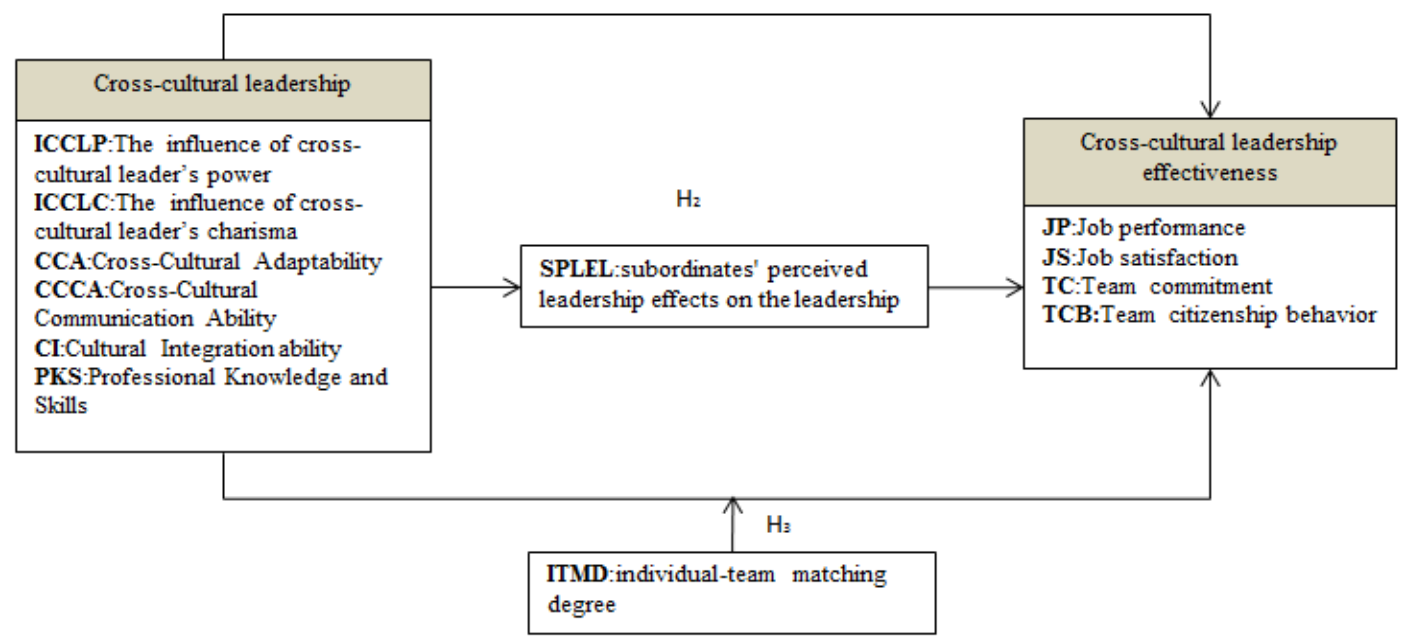

Fig3. The theoretical model of Impact Mechanism of Cross-Cultural Leadership to Leadership Effectiveness According to the cross-cultural leadership six variables divide into six hypotheses as follows:

$\mathbf{H}_{3 \mathbf{a}}$ : The main effect of ICCLP on JP, JS, TC and TCB is regulated by ITMD and appear differences;

$\mathbf{H}_{\mathbf{3}}$ : The main effect of ICCLC on JP, JS, TC and TCB is regulated by ITMD and appear differences;

$\mathbf{H}_{3 \mathbf{c}}$ : The main effect of CCA on JP, JS, TC and TCB is regulated by ITMD and appear differences;

H3d: The main effect of CCCA on JP, JS, TC and TCB is regulated by ITMD and appear differences;

H3e: The main effect of PKS on JP, JS, TC and TCB is regulated by ITMD and appear differences;

$\mathbf{H}_{3 \mathbf{f}}$ : The main effect of CI on JP, JS, TC and TCB is regulated by ITMD and appear differences; We can establish a theoretical model shown in Fig.3.

\section{EMPIRICAL RESEARCH}

\subsection{Scale Design}

German CCT leadership model fieldwork Questionnaire is divided into two parts including Leaders Scale and Subordinates Scale.

Leaders Scale mainly related to the variables of leaders, including ICCLP, CCA,CCCA,CI and PKS; Subordinates Scale mainly related to the variables of Subordinates, including JP, JB, TC, TCB,ITMD and SPLEL, and the reference object variables (ICCLC) by the subjective opinion of subordinates.

A total of 121 teams (a team may include 1 leader and 3 4 subordinates) which from the SinoGerman CCT of German T Group were investigated by filling out the Leaders Scale and Subordinates Scale on the leadership effectiveness questions. Finally, 121 sets of scales were distributed and 107 sets of scales were reclaimed including 107 Leaders Scales and 375 Subordinates Scales in this study.

\subsection{Re liability and Validity of Scale}

We had took a reliability analysis of the Scale according to the Cronbach a coefficient (see Table 1), and also had took a validity analysis of the Scale in terms of confirmatory factor analysis (see Table 2).

Since Table 1 the Cronbach a of every factor is greater than 0.7 , and the results of confirmatory factor analysis in Table 2 are within the acceptable range, thus shows good reliability and validity indicators.

Table1. Cronbach a coefficients of the scale

\begin{tabular}{|l|l|l|l|}
\hline \multicolumn{2}{|c|}{ Variables } & Item umber & Cronbach $\alpha$ \\
\hline Mediator Variable & SPLEL & 5 & 0.802 \\
\hline moderator variable & ITMD & 8 & 0.794 \\
\hline \multirow{2}{*}{$\begin{array}{l}\text { Outcome Variable } \\
\text { (Leadership effectiveness) }\end{array}$} & JP & 7 & 0.811 \\
\cline { 2 - 4 } & JS & 5 & 0.808 \\
\cline { 2 - 4 } & TC & 6 & 0.788 \\
\cline { 2 - 4 } & TCB & 5 & 0.796 \\
\hline
\end{tabular}


Table2. The results of confirmatory factor analysis

\begin{tabular}{|l|l|l|l|l|l|l|}
\hline & SPLEL & ITMD & JP & JS & TC & TCB \\
\hline X2/df & 2.851 & 2.799 & 2.810 & 2.851 & 2.783 & 2.794 \\
\hline GFI & 0.912 & 0.953 & 0.898 & 0.911 & 0.931 & 0.925 \\
\hline RMSEA & 0.065 & 0.021 & 0.068 & 0.738 & 0.744 & 0.817 \\
\hline NFI & 0.886 & 0.910 & 0.863 & 0.867 & 0.883 & 0.921 \\
\hline IFI & 0.872 & 0.861 & 0.879 & 0.987 & 0.934 & 0.925 \\
\hline CFI & 0.886 & 0.894 & 0.861 & 0.944 & 0.910 & 0.932 \\
\hline AGFI & 0.994 & 0.983 & 0.986 & 0.991 & 0.979 & 0.993 \\
\hline PNFI & 0.642 & 0.738 & 0.831 & 0.698 & 0.648 & 0.688 \\
\hline
\end{tabular}

\section{DATA ANALYSiS AND ReSUlts}

\subsection{Cross-Cultural Leadership Impact on Leadership Effectiveness}

Samples are divided into Chinese cultural background group and German cultural background group according to the nationality of the team main leader, the purpose of which is to study cross-cultural leadership whether play a role on leadership effectiveness, and the difference of main leader's cultural background whether produce different degrees of effect on leadership effectiveness of the crosscultural leadership.

\subsubsection{Correlation Analysis}

In the Chinese cultural background groups, correlation analysis shows that the cross-cultural leadership and the leadership effectiveness variables have a positive correlation. Table 3 shows the details. Therefore, it can be concluded that the ICCLP, ICCLC, CCA, CCCA, and CI have a more significant relationship with the leadership effectiveness in the Chinese culture background(except PKS).

Table3. The correlation coefficient between the variables in Chinese cultural background groups

\begin{tabular}{|l|l|l|l|l|l|l|}
\hline Spearman'rho & ICCLP & ICCLC & CCA & CCCA & PKS & CI \\
\hline JP & .795 & .746 & .699 & .780 & .200 & .498 \\
\hline JS & -.831 & .742 & .689 & .843 & .191 & .631 \\
\hline TC & -.784 & .766 & .740 & .825 & .009 & .719 \\
\hline TCB & -.721 & .780 & .786 & .766 & .062 & .677 \\
\hline
\end{tabular}

\subsubsection{Regression Analysis}

In order to further clarify the causal relationship between the variables, we take the cross-cultural leadership as the independent variable, and the leadership effectiveness as the dependent variable, with the stepwise regression analysis, shown in Table 4.

Table 4 tells us that in the Chinese culture background, ICCLP has a significant positive effect on JP, but have a significant negative effect on JP, TC and TCB, which is due to the high power influence of leadership will have a negative impact on job satisfaction, team commitment and team citizenship behavior; ICCLC has significantly positive effect on JP, JS, TC and TCB, which shows that the charismatic influence of leadership is the main force to influence the effectiveness of team leadership; CCA and CCCA only had a significant effect on JS, which had no significant effect on the other variables; CI has a significant positive effect on JP, IS and TCB, but PKS does not play a role in the leadership effectiveness. Therefore, it is assumed that $\mathrm{H}_{1 \mathrm{a} 1}-\mathrm{H}_{1 \mathrm{a} 4}$ is revised as follows according to the data analysis:

$$
\begin{aligned}
& \mathrm{H}_{1 \mathrm{a} 1}{ }^{*}: \mathrm{IP}=\mathrm{C}_{\mathrm{C}}(+\mathrm{ICCLP},+\mathrm{ICCLC},+\mathrm{CI}) \\
& \mathrm{H}_{1 \mathrm{a} 2}{ }^{*}: \mathrm{JS}=\mathrm{C}_{\mathrm{C}}(-\mathrm{ICCLP},+\mathrm{ICCLC},+\mathrm{CCA},+\mathrm{CCCA},+\mathrm{CI}) \\
& \mathrm{H}_{1 \mathrm{a} 3}: \mathrm{TC}=\mathrm{C}_{\mathrm{c}}(-\mathrm{ICCLP},+\mathrm{ICCLC}) \\
& \mathrm{H}_{1 \mathrm{a} 4}{ }^{*}: \mathrm{TCB}=\mathrm{C}_{\mathrm{C}}(-\mathrm{ICCLP},+\mathrm{ICCLC}+\mathrm{CI})
\end{aligned}
$$

The revised hypotheses can be verified by data analysis. 
Bin HE et al.

Table4. The regression analysis of Sino-Germany cross-cultural leadership to the leadership effectiveness in Chinese cultural background groups $(N=49)$

\begin{tabular}{|c|c|c|c|c|c|c|c|c|}
\hline $\begin{array}{l}\text { Dependent } \\
\text { variable }\end{array}$ & $\begin{array}{l}\text { Independent } \\
\text { variable }\end{array}$ & B & $\mathrm{R}$ & $\mathrm{R}^{2}$ & Adj. $R^{2}$ & $\mathrm{t}$ & $\mathrm{F}$ & Sig. \\
\hline \multirow[t]{3}{*}{ JP } & ICCLP & 0.387 & 0.581 & 0.337 & \multirow{3}{*}{0.324} & 3.265 & \multirow[t]{3}{*}{26.771} & 0.001 \\
\hline & ICCLC & 0.276 & 0.526 & 0.321 & & 3.215 & & 0.003 \\
\hline & $\overline{\mathrm{CI}}$ & 0.229 & 0.363 & 0.184 & & 2.980 & & 0.005 \\
\hline \multirow[t]{5}{*}{ JS } & ICCLC & 0.473 & 0.622 & 0.387 & \multirow[t]{5}{*}{0.297} & 3.289 & \multirow[t]{5}{*}{35.903} & 0.000 \\
\hline & ICCLP & -0.447 & 0.589 & 0.298 & & 3.256 & & 0.000 \\
\hline & CCCA & 0.283 & 0.461 & 0.212 & & 3.214 & & 0.001 \\
\hline & $\mathrm{CCA}$ & 0.188 & 0.331 & 0.109 & & 2.098 & & 0.002 \\
\hline & CI & 0.067 & 0.323 & 0.104 & & 1.956 & & 0.006 \\
\hline \multirow[t]{2}{*}{$\mathrm{TC}$} & ICCLP & -0.379 & 0.543 & 0.294 & \multirow[t]{2}{*}{0.225} & -2.667 & \multirow[t]{2}{*}{22.709} & 0.001 \\
\hline & ICCLC & 0.166 & 0.410 & 0.168 & & 2.076 & & 0.003 \\
\hline \multirow[t]{3}{*}{ TCB } & ICCLC & 0.389 & 0.517 & 0.267 & \multirow[t]{3}{*}{0.189} & 2.389 & \multirow[t]{3}{*}{26.097} & 0.000 \\
\hline & $\mathrm{CI}$ & 0.290 & 0.361 & 0.130 & & 2.321 & & 0.002 \\
\hline & ICCLP & -0.167 & 0.422 & 0.119 & & -2.216 & & 0.002 \\
\hline
\end{tabular}

In order to test the research hypotheses $\mathrm{H}_{1 \mathrm{~b} 1}-\mathrm{H}_{1 \mathrm{~b} 14}$, the similar correlation analysis and regression analysis also were carried on in German cultural background groups. The results of the correlation analysis have shown that ICCLC, PKS, CCA, CCCA, PKI and leadership effectiveness have different degrees of correlation. The results of the regression analysis have shown that: (1) ICCLC had a significant regression effect on TC and TCB ;(2) CCA had a significant regression effect on TC;(3) CI had a significant regression effect on JP, JS and TCB;(4) CCCA had a significant regression effect on JS;(5) PKI had a significant effect on JP and JS regression. Therefore, the hypotheses $\mathrm{H}_{1 \mathrm{~b} 1}-\mathrm{H}_{1 \mathrm{~b} 4}$ also were similar revised, re-test, and re-verified.

$$
\begin{aligned}
& \mathrm{H}_{1 \mathrm{~b}}{ }^{*}: \mathrm{JP}=\mathrm{C}_{\mathrm{G}}(+\mathrm{CI},+\mathrm{PKS}) \\
& \mathrm{H}_{1 \mathrm{~b}}{ }^{*}: \mathrm{JS}=\mathrm{C}_{\mathrm{G}}(+\mathrm{CCCA},+\mathrm{CI},+\mathrm{PKS}) \\
& \mathrm{H}_{1 \mathrm{bb}}{ }^{*}: \mathrm{TC}=\mathrm{C}_{\mathrm{G}}(+\mathrm{ICCLC},+\mathrm{CCA}) \\
& \mathrm{H}_{1 \mathrm{~b}}{ }^{*}: \mathrm{TCB}=\mathrm{C}_{\mathrm{G}}(+\mathrm{ICCLC},+\mathrm{CI})
\end{aligned}
$$

It can be concluded that cross-cultural leadership is the power source of leadership effectiveness, and the cross-cultural leadership impact on leadership effectiveness is influenced by the cultural background of the main leader of the team, and it is assumed that $\mathrm{H}_{1}$ is verified.

\subsection{Mediating Effect of Subordinates' Perceived Leadership Effects on the Leadership}

To test the mediating effect of SPLEL in the process of cross-cultural leadership impact on leadership effectiveness, the independent variable (cross-cultural leadership six variables: ICCLP, ICCLC, CCCA, CCA, CI and PKS), the dependent variable (leadership Effectiveness four variables: JP, JS, TC and TCB), he mediating variables (SPLEL) were tested in this paper, which shown in Table5.

Table5. The mediating effect test procedure

\begin{tabular}{|l|l|l|l|}
\hline Step & Purpose & Contents & Result \\
\hline First & $\begin{array}{l}\text { Examine the role of the } \\
\text { independent variable on } \\
\text { the dependent variable }\end{array}$ & $\begin{array}{l}\text { (1)24 times regression } \\
\text { analysis of Cross-cultural } \\
\text { Leadership six variables on } \\
\text { leadership effectivenes four } \\
\text { variable; } \\
\text { (2) 4 times regression } \\
\text { analysis of cross-cultural } \\
\text { leadership six variables } \\
\text { togetheron leadership } \\
\text { effectiveness four variables } \\
\text { significant impact on the JP, and ICCLC is } \\
\text { the biggest influence; } \\
\text { (b) ICCLP, ICCLC, CCCA, PKS and CI } \\
\text { have a significant impact on the JS and } \\
\text { CCCA is biggest positive influence, ICCLP } \\
\text { produce a negative impact on JS; } \\
\text { (c) ICCLC and CI have a significant impact } \\
\text { on the TC; and ICCLC is biggest positive } \\
\text { influence; } \\
\text { (d) ICCLC, CI, CCCA and CCA have a } \\
\text { significant impact on the TCB, and ICCLC } \\
\text { is biggest influence. }\end{array}$ \\
\hline Second & $\begin{array}{l}\text { Examine the role of } \\
\text { mediating arguments }\end{array}$ & $\begin{array}{l}\text { Regression analysis of Cross- } \\
\text { cultural Leadership six } \\
\text { variables on SPLEL }\end{array}$ & $\begin{array}{l}\text { ICCC, CCA, PKS, ICMLC, CI and CCA } \\
\text { have a significant impact on SPLEL; and } \\
\text { ICCLP is biggest positive influence, } \\
\text { followed by the CCCA, PKS, ICCLC, CI } \\
\text { and CCA. }\end{array}$ \\
\hline
\end{tabular}




\begin{tabular}{|c|c|c|c|}
\hline Third & $\begin{array}{l}\text { Examine the role of } \\
\text { mediating variables on } \\
\text { the dependent variable }\end{array}$ & $\begin{array}{l}\text { Regression analysis of } \\
\text { SPELL on leadership } \\
\text { effectiveness Four Variable }\end{array}$ & $\begin{array}{l}\text { SLPEL has a significant positive impact on } \\
\text { JP, JS, TC and TCB }\end{array}$ \\
\hline Fourth & $\begin{array}{l}\text { Since the role of test } \\
\text { variables mediating } \\
\text { variables on the } \\
\text { dependent variable }\end{array}$ & $\begin{array}{l}4 \text { times regression analys is of } \\
\text { Cross-cultural Leadership six } \\
\text { variables and SPLEL } \\
\text { together on leadership } \\
\text { effectiveness }\end{array}$ & 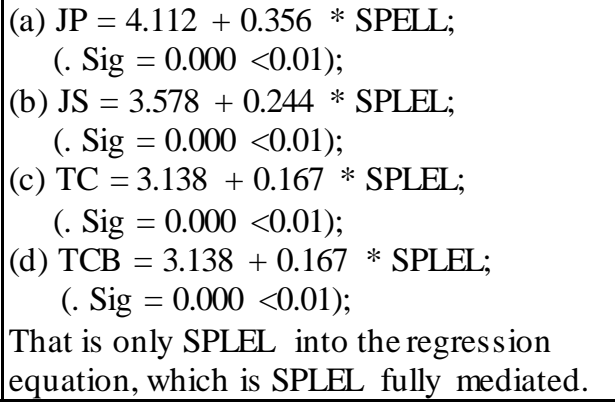 \\
\hline
\end{tabular}

According to the first step of table 5, it shows that cross-cultural leadership has an impact on leadership effectiveness; the second step shows that cross-cultural leadership has a significant effect on SPELE; the third step shows that SPELE has a significant positive effect on leadership effectiveness; the fourth step shows that only SPLEL into the regression equation, which is SPLEL fully mediated. Therefore, it could be assumed that the $\mathrm{H} 2$ has been verified.

\subsection{Moderating Effect of Individual-Team Match Degree}

To test the moderating effect of ITMD, we use hierarchical regression analysis to analyze the variables. The first layer into the regression equation are cross-cultural leadership six variables, the second layer into the equation is ITMD, and the third layer into the regression equation are the crosscultural leadership six variables interact respectively ITMD items.

Observe the decision coefficient and the standard regression coefficient of each layer, the former two layers mainly showed the relationship between the cross-cultural leadership six variables, the ITMD and the leadership effectiveness. And the standard regression coefficient of the interaction term of the third layer can be used to judge whether the member is regulated or not. To save space, the adjustment process effect is written in Table 6. In table 6, the No.(1) line said: the interaction ITMD and ICCLP play a significant regulatory role in JP $(\beta=1.998, p<0.01)$, in JS $(\beta=2.245, p<0.01)$, in TC $(\beta=$ $2.776, \mathrm{p}<0.01)$, but have a medium regulation effect on TCB $(\beta=0.178, \mathrm{p}<0.01)$. It follows that the main effect of ICCLP on JP, JS, TC, and TCB is regulated by ITMD, which support the hypothesis $\mathrm{H}_{3 \mathrm{a}}$. Others numbers in table 6 are similar.

Table6. Moderating Effect of ITMD

\begin{tabular}{|l|l|l|l|l|l|l|}
\hline No. & Interaction & JP & JS & TC & TCB & Conclusion \\
\hline (a) & ITMD and ICCLP & $\begin{array}{l}\mathrm{Y}(\beta=1.998, \\
\mathrm{p}<0.01)\end{array}$ & $\begin{array}{l}\mathrm{Y}(\beta=2.245, \mathrm{p}< \\
0.01)\end{array}$ & $\begin{array}{l}\mathrm{Y}(\beta=2.776, \\
\mathrm{p}<0.01)\end{array}$ & $\begin{array}{l}\mathrm{Y}-(\beta=0.178, \\
\mathrm{p}<0.01)\end{array}$ & Support the hypothesis $\mathrm{H}_{3 \mathrm{a}}$ \\
\hline (b) & ITMD and ICCLC & $\begin{array}{l}\mathrm{Y}(\beta=1.884, \\
\mathrm{p}<0.01)\end{array}$ & $\begin{array}{l}\mathrm{Y}(\beta=0.962, \mathrm{p}< \\
0.01)\end{array}$ & $\begin{array}{l}\mathrm{Y}(\beta=1.472, \\
\mathrm{p}<0.01)\end{array}$ & $\begin{array}{l}\mathrm{Y}(\beta=0.867, \\
\mathrm{p}<0.01)\end{array}$ & Support the hypothesis $\mathrm{H}_{3 \mathrm{~b}}$ \\
\hline (c) & ITMD and CCA & $\mathrm{N}$ & $\mathrm{N}$ & $\mathrm{N}$ & $\mathrm{N}$ & Not support the hypothesis $\mathrm{H}_{3 \mathrm{c}}$ \\
\hline (d) & ITMD and CCCA & $\begin{array}{l}\mathrm{Y}(\beta=0.677, \\
\mathrm{p}<0.01)\end{array}$ & $\begin{array}{l}\mathrm{Y}(\beta=0.534, \mathrm{p}< \\
0.01)\end{array}$ & $\mathrm{N}(\beta=0.054)$ & $\begin{array}{l}\mathrm{Y}-(\beta=0.154, \\
\mathrm{p}<0.05)\end{array}$ & Partially support hy pothesis $\mathrm{H}_{3 \mathrm{~d}}$ \\
\hline (e) & ITMD and PKS & $\begin{array}{l}\mathrm{Y}(\beta=0.387, \\
\mathrm{p}<0.01)\end{array}$ & $\begin{array}{l}\mathrm{Y}-(\beta=0.241, \\
\mathrm{p}<0.05)\end{array}$ & $\begin{array}{l}\mathrm{Y}-(\beta=0.164, \\
\mathrm{p}<0.05)\end{array}$ & $\mathrm{N}(\beta=0.107)$ & Partially support hy pothesis $\mathrm{H}_{3 \mathrm{e}}$ \\
\hline (f) & ITMD and CI & $\begin{array}{l}\mathrm{Y}(\beta=0.421, \\
\mathrm{p}<0.01)\end{array}$ & $\begin{array}{l}\mathrm{Y}-(\beta=0.243, \\
\mathrm{p}<0.05)\end{array}$ & $\begin{array}{l}\mathrm{Y}(\beta=0.322, \\
\mathrm{p}<0.01)\end{array}$ & $\begin{array}{l}\mathrm{Y}-(\beta=0.132, \\
\mathrm{p}<0.05)\end{array}$ & Support the hypothesis $\mathrm{H}_{3 \mathrm{f}}$ \\
\hline
\end{tabular}

[Note] Y: Play a significant regulatory role $(\beta>0.3$ and $p<0.01)$; $\mathrm{Y}$-: Play a medium regulatory role $(0.1<\beta<0.3$ and $\mathrm{p}<0.01)$; $\mathrm{N}$ : no significant regulatory role $(\beta<0.1$ or $\mathrm{p}>0.05)$ 。

\section{Conclusions AND Prospects}

\subsection{Conclusions}

Using empirical methods, the research chooses CCT in German Group T as the research object to study the impact mechanism of Sino-German cross-cultural team leadership. From this research, we can make clear the impact mechanism of cross-cultural leadership on leadership effectiveness. The main conclusions are as follows:

(a) In the Sino-German cross-cultural leadership team, cross-cultural leadership is the power of leadership effectiveness. The impact of cross-cultural leadership on leadership effectiveness is influenced by the main cultural background of team main leaders. 
In Chinese culture background teams, ICCLC is the most important power that has impact on the team leader effectiveness (including JP, JS, TC and TCB), while the higher ICCLP will reduce the JS of the subordinates and the CCA and CCCA have significant effect on JS. In addition, PKS has no significant impact on leadership effectiveness for Chinese leaders put more emphasis on ICCLP.

In German culture background team, leader's PKS and CI have great effect on leadership effectiveness (especially JP and JS), ICCLC has a significant impact on the leadership effectiveness, while CCA had no significant effect on JP and JS, and CCCA also had no significant effect on JP, TC and TCB. This is because ICCLC showed more professionalism in German culture background team. From the starting point of the professionalization and standardization, German people believe that the leader who has the higher professional quality is easier to obtain the trust of members and followers. In addition, employees have accepted a certain degree of cross-cultural training in German Group T, therefore, CCA and CCCA between the groups have no large difference, and thus have no significant impact to the leadership effectiveness.

(a) In the Sino-German cross-cultural team, SPLEL plays a mediate role between cross-cultural leadership and leadership effectiveness.

(b) ITMD has a significant moderating effect on cross-cultural leadership and leadership effectiveness.

The fitness of individual and various factors of team (such as boss, work environment, work style, organization structure, etc.) are not the same degree, and this kind of individual differences will affect the leadership performance, especially in cross-cultural teams. Therefore, enterprises and social organizations, who take cross-cultural teams as main organizational forms, must put the ITMD in an important position.

In conclusion, the results show that cross-cultural leadership is the power source of leadership effectiveness, while cross-cultural leadership has impact on the leadership effectiveness through the intermediary variable-SPLEL, its process is also restricted by individual-team matching degree; in addition, leadership effectiveness is influenced by the cultural background of principal leaders in the team.

\subsection{Prospects}

First, sample complement: effective samples in this research are only 107 sets (107 of leader, 375 of subordinates). If we have enough time to take a large sample investigation and be allowed to stratify sampling, it can ensure better the external validity of samples.

Second, it is necessary to do research further to discuss which strategies can improve better the effectiveness of cross-cultural leadership.

Third, from the perspective of cross-cultural leaders, the research studies the impact mechanism of cross-cultural leadership on leadership effectiveness. However, with the development of theories, the future research direction is to study the influence mechanism of the cross-cultural followership on leadership effectiveness from the perspective of cross-cultural followers. It has a certain degree of theoretical and practical significance for the study of cross-cultural leadership and cross-cultural theory.

\section{ACKNOWLEDGEMENTS}

This work is supported by the Philosophy and Social Science Foundation of Guangdong Province und er Grant No.GD15CGL03 and GD15XGL37, and partly supported by Grant No.2013S03 and Grant N o.2014KQNCX192.

\section{REFERENCES}

[1] He, B., Li, Z.Y., \&Zheng, H. (2014). The Content Structure of Cross-Cultural Leadership and Its Confirmation Research. Economic Management Journal, 36(12),83-94.

[2] Zheng, H. (2014). Research on Impact Mechanism of Cross-Cultural Leadership on Leadership Effectiveness. Guangdong University of Technology.

[3] Shu, S. F. (2014). The Rise, Challenges and Responses of Cross-cultural Leadership. Teaching and Research. (10),60-66.

[4] Chen, X.P.(2009). Managing Across Cultures.Tsinghua University Press. 
[5] Brodbeck, F. C., Frese, M., Akerblom, S., Audia, G., Bakacsi, G., \& Bendova, H., et al. (2000). Cultural variation of leadership prototypes across 22 european countries. Journal of Occupational \& Organizational Psychology, 73(1), 1-29.

[6] Hartog, D. N. D., House, R. J., Hanges, P. J., Ruiz-Quintanilla, S. A., \& Dorfman, P. W. (1999). Culture specific and cross-culturally generalizable implicit leadership theories: are attributes of charismatic/transformational leadership universally endorsed? Leadership Quarterly, 10(2), 219256.

[7] Ensari, N., Murphy, S. E. (2003). Cross-cultural variations in leadership perceptions and attribution of charisma to the leader. Organizational Behavior \& Human Decision Processes, 92(1-2), 52-66.

[8] Elenkov, D. S., \& Manev, I. M. (2005). Top management leadership and influence on innovation: the role of sociocultural context. Journal of Management, 31(3), 381-402.

[9] Spitzberg, B.H. (1998). A Model of Intercultural Communication Competence. Wadsworth Publishing,Belmont,CA.

[10] Thoms, P., \& Greenberger, D. B. (1995). The relationship between leadership and time orientation. Journal of Management Inquiry, 4(3), 272-292.

[11] Koontz, H. (1980). The management theory jungle revisited. Academy of Management Review, 5(2), 3-17.

[12] Weihrich, H. (1979). How to change a leadership pattern. Management Review, 68(4),26

[13] Bennis, W., \& Goldsmith, J. (1997). Learning to Lead: A Workbook on Becoming a Leader. Perseus Books.

[14] Allameh, S. M., Pool, J. K., Kazemi, R. V., \& Mostafavi, M. (2015). The impact of emotional intelligence on transformational leadership and leader effectiveness. Latin American Journal of Management for Sustainable Development, 2(1),. 83-93.

[15] Torres, L. E., Ruiz, C. E., Hamlin, B., \& Velez-Calle, A. (2015). Perceived managerial and leadership effectiveness in colombia. European Journal of Training \& Development, 39, 203219.

[16] Deng, Z. H., Chen, W. Z. (2014).A Study on Performance Differences of Different Leadership Styles from the Perspective of Corporate Culture. East China Economic Management, 28(12), 117-120.

[17] Hu, H.J., Weng, Q.X., Cao, W.L.. (2015). The Relationship between Charismatic Leadership and Performance: A Meta-Analysis. Chinese Journal of Management, 12(2),223-230.

[18] Yu, H.B., Guan, X.Y., Zheng, X.M..(2014). Paternalistic Leadership Creates Work Performance, Servant Leadership Delivers Job Satisfaction: Integration of Two Types of Leadership Behaviors. Science of Science and Management of S. \&.T. 35(06), 172-180.

[19] Lin, C.P., Zhuang, B.C. (2014). The impact of paternalistic leadership on management innovation: an integrated model. Studies in Science of Science, 32(4),622-640.

[20] Butler, A. M., Kwantes, C. T., \& Boglarsky, C. A. (2014). The effects of self-awareness on perceptions of leadership effectiveness in the hospitality industry: a cross cultural investigation. International Journal of Intercultural Relations, 40(2), 87-98.

[21] Li, P., Yong, H.Y., Zhu, D.Q. (2014). An Empirical Study on the Efficacy of Transformational Leadership in School. Research in Educational Development, (15), 88-92.

[22] Wu, W.K., Liu, J., Zhang, L. (2003). Value Based Leadership: An Empirical Test of Chinese CEO's. Journal of Industrial Engineering and Engineering Management, (4),76-83.

[23] Zhou, W.J., Song, J.W., Li, H.L. (2015). The Definition, Structure and Measurement of Followership in Chinese Context. Chinese Journal of Management, 12(03), 355-363.

[24] Xu, S. (2013). Followership: Connotation Influencing Factors, and the Mechanism of Followership on Leadership Effectiveness. Jiangxi University of Finance and Economics.

[25] Yuan, T., Ling, W.Q. (2010). Research on Followership: Review and Prospect. Advances in Psychological Science, (05),769-780.

[26] Yao, Y.H., Jiang, F.J. (2008). Research on Leaders Performance in Different Organizational Culture. Soft Science, ,22(10),110-113.

[27] Miller, R.L., Butter,J., Cosentino, C.J. (2004). Followership Effectiveness: an Extension of 
Fiedler's Contingency Model. Leadership\& Organization Development Journal, 25(4), 362-368.

[28] Fiedler, F. E. (1971). Validation and extension of the contigency model of leadership effectiveness: a review of empirical findings.. Psychological Bulletin, 76(2), 128-148.

[29] House, R.J., Baetz, M.L.(1979). Leadership: Some Empirical Generalizations and New Research Directions. Research in Organizational Behavior, 1, 341.

[30] Li, X. Q., Lin, Z. Y. (2013). Transformational, Transactional Leadership and Leadership Effectiveness: The Mediating Effects of Leader-member Exchange. Journal of Chongqing University (Social Science Edition), 19(6), 56-64.

[31] Qu, Q., He, Z. C., Mei, Z. Q.(2013).An Empirical Study on the Impact of Leader Humility on Leadership Effectiveness and Employees' Organizational Identification. China Soft Science, (7), 101-109.

[32] Li, J., Li, Y., Cai, Z. Y., Zhu, H., Wang, X.R..(2013). Regional differences in a national culture and their effects on leadership effectiveness: A tale of two neighboring Chinese cities. Journal of World Business, 48(1),13-19.

[33] Bruno, L. F. C., \& Lay, E. G. E. (2008). Personal values and leadership effectiveness. Journal of Business Research, 61(6), 678-683.

[34] Wu, Z. M., Wu, X. (2006). An empirical study on the relationship among transformational leadership, organizational citizenship behavior and team effectiveness in high-tech work teams. Science Research Management, 27(6), 74-79.

[35] Wang, Z., Sun, J.M., Zhao, Y. J. (2012).Leadership Effectiveness in the Chinese Context: A Meta-Analysis of Transformational Leadership, Leader-Member Exchange and Abusive Supervision. Advances in Psychological Science, 20(2),174-190.

[36] Sonnentag, S., \& Frese, M. (2005). Performance Concepts and Performance Theory. Psychological Management of Individual Performance. John Wiley \& Sons, Ltd.

[37] Bono, J. E., \& Judge, T. A. (2003). Self-concordance at work: toward understanding the motivational effects of transformational leaders. Academy of Management Journal, 46(5), 554571.

[38] Tang, L.L. (2009). Conceptual Model and Effectiveness Mechanism of Organizational Change Leadership. ZheJiang University.

[39] Li, C. P., Meng, H., Shi, K. (2007). A Comparative Study on the Relationship of Transformational Leadership, Paternalistic Leadership, and the PM theory with Leadership Effectiveness. Psychological Science,(06),1477-1481.

[40] Xie, Y., Huo, G.Q., Zhang, X.D.(2013). The study on the leadership models of scientific research teams in China. Studies in Science of Science, 31(1),79-84.

[41] A Nahavandi. (2000). The Art and Science of Leadership. Upper Saddle River: Prentice Hall.

[42] Zenger, J. H., \& Folkman, J.R.. (2009). The Extraordinary Leader. Mcgraw-Hill Publ. Comp.

[43] Yuan, L., Li, Y.(2012). A comparison of Sino German enterprise culture and enterprise management-A Theoretical frame of cultural value based on Hofstede. Commercial Times, (03), 35-37.

[44] Chen, X., Zhu, X. (2015). The Development of Library Leadership at Abroad: A Literature Review, Journal of Academic Libraries, 33(1), 34-42.

[45] Li, C. C. (2014). Brief Discussion on German Rule-Following and Its Culturally Contributing Factor. Social Sciences in Nanjing, (9), 76-81.

[46] Paul.Hersey. (2003). The Situational Leader. China Financial and Economic Publishing Hose.

[47] Meng,Y., Liang, Q.Z., Zhang, J., Yuan, B.(2014). The Relationship between the Essence of Team Strategic Leadership and Follower Job Performance-Positive Organizational Behavior Perspective. Soft Science, 28(1):72-76.

[48] Cogliser, C. C., Schriesheim, C. A., Scandura, T. A., \& Gardner, W. L. (2009). Balance in leader and follower perceptions of leader-member exchange: relationships with performance and work attitudes. Leadership Quarterly, 20(3), 452-465.

[49] Mietzel, G. (2007). Wege In Die Psychologie. Central Compilation and Translation Press.

[50] Shu, Y. S. (2005). Mechanics. Peking University Press. 